\title{
Molecular Identification of Mycobacterium Species of Public Health and Veterinary Importance from Cattle in the South State of México
}

\author{
Adrian Zaragoza Bastida, ${ }^{1,2}$ Nallely Rivero Pérez, ${ }^{2}$ \\ Benjamín Valladares Carranza, ${ }^{3}$ Keila Isaac-Olivé, ${ }^{1}$ Pablo Moreno Pérez, ${ }^{1}$ \\ Horacio Sandoval Trujillo, ${ }^{4}$ and Ninfa Ramírez Durán ${ }^{1}$ \\ ${ }^{1}$ Facultad de Medicina, Universidad Autónoma del Estado de México, Paseo Tollocan/Jesús Carranza s/n, 50180 Toluca, MEX, Mexico \\ ${ }^{2}$ Área Académica de Medicina Veterinaria y Zootecnia, Instituto de Ciencias Agropecuaria, \\ Universidad Autónoma del Estado de Hidalgo, Av. Universidad Km 1, Ex-Hda. de Aquetzalpa, 43600 Tulancingo, HGO, Mexico \\ ${ }^{3}$ Centro de Investigación y Estudios Avanzados en Salud Animal, Facultad de Medicina Veterinaria y Zootecnia, \\ Universidad Autónoma del Estado de México, Km 15.5 Carretera Panamericana Toluca-Atlacomulco, 50200 Toluca, MEX, Mexico \\ ${ }^{4}$ Departamento de Sistemas Biológicos, Universidad Autónoma Metropolitana-Xochimilco, Calzada del Hueso 1100, \\ 04960 Ciudad de México, Mexico
}

Correspondence should be addressed to Ninfa Ramírez Durán; nramirezd@uaemex.mx

Received 9 March 2017; Revised 12 May 2017; Accepted 21 May 2017; Published 14 June 2017

Academic Editor: Nahuel Fittipaldi

Copyright ( 2017 Adrian Zaragoza Bastida et al. This is an open access article distributed under the Creative Commons Attribution License, which permits unrestricted use, distribution, and reproduction in any medium, provided the original work is properly cited.

\begin{abstract}
Mycobacterium genus causes a variety of zoonotic diseases. The best known example is the zoonotic tuberculosis due to M. bovis. Much less is known about "nontuberculous mycobacteria (NTM)," which are also associated with infections in humans. The Mexican standard NOM-ZOO-031-1995 regulates the presence of M. bovis in cattle; however, no regulation exists for the NTM species. The objective of this study was to isolate and identify nontuberculous mycobacteria species from cattle of local herds in the south region of the State of Mexico through the identification and detection of the $100 \mathrm{bp}$ molecular marker in the 23S rRNA gene with subsequent sequencing of the $16 \mathrm{~S}$ rRNA gene. Milk samples (35) and nasal exudate samples (68) were collected. From the 108 strains isolated, 39 were selected for identification. Thirteen strains isolated from nasal exudates amplified the $100 \mathrm{bp}$ molecular marker and were identified as M. neoaurum (six strains), M. parafortuitum (four strains), M. moriokaense (two strains), and M. confluentis (one strain). Except $M$. parafortuitum, the other species identified are of public health and veterinary concern because they are pathogenic to humans, especially those with underlying medical conditions.
\end{abstract}

\section{Introduction}

The genus Mycobacterium causes a wide variety of zoonotic diseases. The best known example is zoonotic tuberculosis due to M. bovis, for which cattle is the main reservoir. M. bovis is part of the "tuberculosis complex," which also includes the species M. tuberculosis, M. africanum, M. caprae, and $M$. microti [1].

Within the mycobacterial group are the "nontuberculous mycobacteria (NTM)," which are also associated with infections in humans. The NTM are found in various environmental sources such as soil, water, vegetation, animals, dairy products, and feces and may be transmitted inadvertently by inhalation, ingestion, or skin penetration [2].

The Mexican standard NOM-ZOO-031-1995 regulates the presence of $M$. bovis in cattle to control and eradicate bovine tuberculosis (bTB); however, no regulation exists for the NTM species. The official diagnosis of bovine tuberculosis due to the presence of $M$. bovis at the field level is based on the intradermal test using a purified protein derivative (tuberculin) [3]. Although used for several years, this test does not provide good sensitivity and specificity. Approximately $20 \%$ of the animals with tuberculosis do not react to the test [4], and the presence of other mycobacterial species, both 
tuberculosis complex and NTM species, causes interference that leads to false-positive and false-negative diagnoses.

Although Mexico has a regulatory standard, bTB prevalence in excess of $2 \%$ is reported in some areas [5]. Given the poor specificity and sensitivity of the tuberculin test, the actual presence of $M$. bovis is likely to be lower and the infection rate of cattle by other mycobacteria is likely to be higher, respectively. Thus, cattle breeders, veterinarians, technicians, and employees working in the livestock industry might be occupationally exposed to infections by M. bovis and NTM. Very little is known about occupational exposure to zoonoses due to NTM species because the identification of these species was a rather difficult task prior to the development of identification techniques based on molecular biology.

Currently, the molecular biology techniques most commonly used for the diagnosis of diseases caused by mycobacteria are restriction fragment length polymorphism (RFLP) for the diagnosis of $M$. tuberculosis [6], spoligotyping for the diagnosis of M. bovis [7], and the detection of a 100-base pair (bp) "specific insertion" located on the 23S rRNA gene characteristic of Gram-positive bacteria with a high guaninecytosine (HGC) content, which is considered a molecular marker for this group of bacteria [8,9], followed by sequence analysis of the $16 \mathrm{~S}$ rRNA gene for the identification of bacteria at the species level [10].

Among the NTM species identified by the aforementioned techniques are M. balnei, M. marinum, and M. platypoecilus, which have caused superficial and deep skin lesions [11]; M. kansasii from lung lesions [12]; M. simiae from generalized infections [13]; M. scrofulaceum from infections of the skin and internal organs [14]; M. szulgai associated with pulmonary infections, osteomyelitis, tenosynovitis, and lymphadenitis [15]; M. ulcerans associated with subcutaneous granulomas [16]; M. fortuitum and M. chelonae associated with vasculitis, endocarditis, osteomyelitis, mediastinitis, meningitis, keratitis, and hepatitis [17]; M. abscessus, associated with erythematous lesions that progressed to ulcerated nodules [18]; and other species.

The largest percentage of the state inventory for heads of cattle in the State of Mexico in Mexico is concentrated in the southern region, and one of the main economic activities is cattle ranching [19]. The Mexican regulation for cattle control NOM-ZOO-031-1995 only focuses on the tuberculin test for the diagnosis of M. bovis. Little is known about the presence of NTM in the cattle of the region. Given the possibility of identifying species of actinobacteria by detection of the 100base pair molecular marker on the $23 \mathrm{~S}$ rRNA gene and the subsequent sequencing of the $16 \mathrm{~S}$ rRNA gene, it is possible to identify the aforementioned NTM species.

The objective of the present study was to isolate and identify NTM species from cattle of the south region of the State of Mexico. The Mycobacterium species were isolated from samples of nasal exudate and bovine milk and identified by detecting the 100-base pair molecular marker in the $23 \mathrm{~S}$ rRNA gene with subsequent sequencing of the 16S rRNA gene.

\section{Materials and Methods}

2.1. Sampling. A sampling was performed based on the spatial distribution of herds positive for bovine tuberculosis in the state of Mexico conducted by Zaragoza et al. 2015 [20]. Four herds of cattle were selected in the south region of the State of Mexico, one herd belonging to the Municipality of Temascaltepec and three herds belonging to the municipality of Zacazonapan. A total of 103 samples, 35 milk samples and 68 samples of nasal exudate, were collected. The distribution of the number and type of samples collected in each herd is shown in Table 1.

2.2. Obtaining Samples of Milk and Nasal Exudate. The udder and nipples were cleansed with purified water and soap and then dried with paper towels, and nipple asepsis was subsequently performed using swabs soaked in $70 \%$ alcohol. Five milliliters of milk was collected directly from the nipple in sterile $20 \mathrm{~mL}$ vessels, discarding the initial flow. Nasal exudate was collected directly from the inside of the nasal orifice using a $10 \mathrm{~cm}$ long sterile swab, which was then submerged in an isotonic saline solution $(0.85 \%)$. Samples of milk and nasal exudate were stored at $4^{\circ} \mathrm{C}$ until processing.

\subsection{Sample Processing}

2.3.1. Isolation of Mycobacteria. The milk samples were centrifuged at 2500 revolutions per minute (rpm) for 10 minutes. The pellets from the milk and nasal exudate samples were inoculated into the following culture medium selective for mycobacteria: Stonebrink (BD BBL 220504), Middlebrook (BD BBL 254521), and Middlebrook (BD BBL 254521) supplemented with $6 \mathrm{~g}$ of sodium pyruvate per liter (Middlebrook$\mathrm{P}$ ). The inoculated media were incubated at $37^{\circ} \mathrm{C}$ for 8 weeks and were assessed every 3 days.

2.3.2. Classification of Isolated Strains. The isolated strains were distributed in groups according to the following characteristics: colony pigmentation, growth time, and colony characteristics (shape, consistency, texture, and pigment production). Isolated strains were stained with Ziehl-Neelsen to confirm the presence of acid-fast bacilli (AFB) [21].

2.4. DNA Extraction. Strains with microscopic characteristics similar to mycobacteria (acid-fast positivity) and two representative strains of each group were selected for identification. To obtain biomass, the strains were inoculated into $30 \mathrm{~mL}$ of Middlebrook liquid culture medium (BD BBL 254521) in $125 \mathrm{~mL}$ flasks and incubated at $37^{\circ} \mathrm{C}$ for 7 days. The liquid medium was transferred to sterile $15 \mathrm{~mL}$ Falcon tubes and centrifuged for 15 minutes at 14,000 rpm. Then, the supernatant was removed and the pellet was transferred to $1.5 \mathrm{~mL}$ Eppendorf tubes; the tubes were then centrifuged at $14,000 \mathrm{rpm} \times 5$ minutes, and the supernatant was discarded. DNA extraction was performed on the resulting pellet using the Wizard Genomic DNA Purification kit (Promega A1120). 
TABLE 1: Samples collected in cattle herds in the south region of the State of Mexico.

\begin{tabular}{|c|c|c|c|c|c|}
\hline Characteristic & Herd 1 & Herd 2 & Herd 3 & Herd 4 & Total \\
\hline Municipality & Temascaltepec & Zacazonapan & Zacazonapan & Zacazonapan & \\
\hline Breed & F1 Swiss-Cebu & Holstein Friesian & Holstein Friesian & Holstein Friesian & \\
\hline $\begin{array}{l}\text { Geographic } \\
\text { location }\end{array}$ & $\begin{array}{c}\mathrm{La}-19^{\circ} 03^{\prime} 13.7^{\prime \prime} \text { Lo- } \\
100^{\circ} 13^{\prime} 36.7^{\prime \prime}\end{array}$ & $\begin{array}{c}\text { La- } 19^{\circ} 03^{\prime} 39.5^{\prime \prime} \text { Lo- } \\
100^{\circ} 16^{\prime} 30.9^{\prime \prime}\end{array}$ & $\begin{array}{c}\text { La- } 19^{\circ} 04^{\prime} 0.4^{\prime \prime} \text { Lo- } \\
100^{\circ} 15^{\prime} 11.5^{\prime \prime}\end{array}$ & $\begin{array}{c}\mathrm{La}-19^{\circ} 03^{\prime} 41^{\prime \prime} \mathrm{Lo}- \\
100^{\circ} 16^{\prime} 06^{\prime \prime}\end{array}$ & \\
\hline History of bTB & Prevalence $0.2 \%{ }^{*}$ & Prevalence $0.2 \%^{*}$ & Prevalence $0.2 \%{ }^{*}$ & Prevalence $0.2 \%{ }^{*}$ & \\
\hline \multicolumn{6}{|c|}{ Samples obtained } \\
\hline Milk & 15 & 20 & 0 & 0 & 35 \\
\hline \multirow[t]{2}{*}{ Nasal exudate } & 0 & 18 & 23 & 27 & 68 \\
\hline & & & & & 103 \\
\hline
\end{tabular}

La: latitude; Lo: longitude; bTB: bovine tuberculosis. ${ }^{*}$ Information obtained from the Committee on the Promotion and Protection of Livestock of the State of Mexico.

2.5. Detection of the Molecular Marker in the 23S rRNA Gene. The $100 \mathrm{bp}$ molecular marker located on the 23S rRNA gene was amplified according to the methodology described by Roller et al. (1992) using the following primers [8]:

23S InsF, 5' -(AC)A(AGT)GCGTAG(AGCT)CGA(AT)GG-3', and 23S InsR, $5^{\prime}$-GTG(AT)CGGTTT(AGCT)(GCT)GGTA-3'.

The reaction was conducted using a commercial Taq DNA polymerase (Promega M1661). The following thermal cycle conditions were used: a predenaturation step for 5 minutes $\left(94^{\circ} \mathrm{C}\right) ; 29$ cycles of denaturation for 30 seconds $\left(94^{\circ} \mathrm{C}\right)$, hybridization for 45 seconds $\left(46^{\circ} \mathrm{C}\right)$, and elongation for 50 seconds $\left(72^{\circ} \mathrm{C}\right)$; and, finally, a postelongation cycle of 5 minutes $\left(72^{\circ} \mathrm{C}\right)$. The amplified fragments were confirmed on a $2 \%$ agarose gel stained with ethidium bromide (SIGMA 46065).

2.6. Amplification of the $16 S$ rRNA Gene. Strains that amplified the $100 \mathrm{bp}$ phylogenetic marker were selected for $16 \mathrm{~S}$ rRNA sequencing analysis. The following primers were used for the amplification:

\section{8f: AGAGTTTGATCMTGGCTCAG and 1492r: TAC- GGYTACCTTGTTACGACTT.}

The reaction was conducted using a commercial Taq DNA polymerase (Promega M1661). The following thermal cycle conditions were used: one predenaturation step for 5 minutes $\left(94^{\circ} \mathrm{C}\right) ; 34$ cycles of denaturation for 30 seconds $\left(94^{\circ} \mathrm{C}\right)$, hybridization for 20 seconds $\left(52^{\circ} \mathrm{C}\right)$, and elongation for 1 minute 30 seconds $\left(72^{\circ} \mathrm{C}\right)$; and, finally, a postelongation cycle of 7 minutes $\left(72^{\circ} \mathrm{C}\right)$.

The amplified fragments were confirmed on a $1 \%$ agarose gel stained with ethidium bromide (SIGMA 46065). The products of this amplification were purified using the Amicon Ultra Filter ${ }^{\circledR}$ kit (Millipore UFC901008) and confirmed on a $1 \%$ agarose gel to verify their presence and quality.

2.7. Identification of Mycobacterium Species. The amplified products of the 16S rRNA gene were sent to the Macrogen Sequencing Service, Maryland, USA. The obtained sequences were analyzed and corrected using the BioEdit program [22]. Consensus sequences were constructed from the forward and reverse fragments, which were compared with sequences deposited previously in GenBank of the National Center for Biotechnology Information (NCBI) using the BLAST program [23] and EzTaxon 2.1 [24].

2.8. Phylogenetic Analysis. Sequences of the $16 \mathrm{~S}$ rRNA gene were obtained for the following mycobacterial species from the American Type Culture Collection (ATCC) and the German Collection of Microorganisms and Cell Cultures (DSM): M. neoaurum ATCC ${ }^{25795}$, M. parafortuitum $\mathrm{DSM}^{43528}, M$. moriokaense $\mathrm{DSM}^{44221 \mathrm{~T}}$, and $M$. confluentis $\mathrm{DSM}^{44017 \mathrm{~T}}$. The sequences of the collection strains and those of the strains isolated in the present investigation were aligned with the BioEdit program [22]. Phylogenetic analysis was performed using the maximum parsimony method in MEGA software version 4 [25]. To form the root of the cladogram, the sequence of Pantoea agglomerans DSM 3493 was used.

\section{Results}

The 108 strains isolated from the 103 collected samples were distributed in 13 groups according to their macroscopic and microscopic morphological characteristics (Table 2). Groups 11 and 12, particularly, were composed of acid-fast strains.

For identification at the species level, 39 strains were chosen: 10 of them belonged to group 11 and 7 to group 12. Two strains from each one of the remaining 11 groups were selected to complete the 39 strains. The $100 \mathrm{bp}$ molecular marker was found in the 33\% (13/39) of the selected strains. For them, the 16S rRNA gene was amplified for sequencing and identification at the species level.

The overall prevalence of NTM on the collected samples was $12.6 \%$ (13/103) considering both milk and nasal exudate samples. However, the specific prevalence for nasal exudate samples was $19.1 \%(13 / 68)$.

According to the sequence comparison, four NTM species of the genus Mycobacterium were identified; 64\% (6/13) of the strains had $98 \%$ and $99 \%$ of similarities with $M$. neoaurum, while $31 \%$ (4/13) had 99\% similarity with $M$. parafortuitum, $15 \%(2 / 13)$ had similarities of $98 \%$ and $99 \%$ with 
TABLE 2: Isolated strains are grouped according to their morphological characteristics and the presence of the molecular marker (100 bp) on the $23 \mathrm{~S}$ rRNA gene.

\begin{tabular}{|c|c|c|c|c|c|}
\hline \multirow{3}{*}{ Group } & \multirow{3}{*}{ Number of Strains } & \multicolumn{3}{|c|}{ Morphological characteristics } & \multirow{3}{*}{$\begin{array}{c}\text { Molecular marker (bp) } \\
\text { 23S rRNA }\end{array}$} \\
\hline & & \multicolumn{2}{|c|}{ Macroscopic } & \multirow{2}{*}{$\begin{array}{l}\text { Microscopic } \\
\text { Ziehl-Neelsen }\end{array}$} & \\
\hline & & Pigmentation & Appearance & & \\
\hline 1 & 29 & Yellow & Creamy & - & 250 \\
\hline 2 & 10 & White & Creamy & - & 250 \\
\hline 3 & 14 & White & Dry & - & 250 \\
\hline 4 & 2 & Salmon & Creamy & - & 250 \\
\hline 5 & 2 & Salmon & Dry & - & 250 \\
\hline 6 & 2 & White, dark & Creamy & - & 250 \\
\hline 7 & 2 & White & Creamy & - & 250 \\
\hline 8 & 3 & White, dark & Dry & - & 250 \\
\hline 9 & 4 & White & Dry & - & 250 \\
\hline 10 & 10 & White & Creamy, dry & - & 250 \\
\hline 11 & 10 & White & Dry & + & 350 and 250 \\
\hline 12 & 7 & Yellow & Creamy & + & 350 \\
\hline 13 & 13 & White & Dry & - & 250 \\
\hline
\end{tabular}

-: absence of acid-fast bacilli; +: presence of acid-fast bacilli; Bp: base pairs.

TABLE 3: Comparison of $16 \mathrm{~S}$ rRNA gene sequences of strains isolated from cattle with those documented in GenBank, using BLAST and EzTaxon.

\begin{tabular}{|c|c|c|c|c|c|c|c|}
\hline Strain & Origin of the herd & Culture medium & Amplified fragment size (bp) & Similarity (Blast) & $\%$ & Similarity (EzTaxon) & $\%$ \\
\hline $1-A Z$ & 2 & Middlebrook & 1428 & M. neoaurum & 98 & M. neoaurum & 98.3 \\
\hline $2-\mathrm{AZ}$ & 2 & Stonebrink & 1408 & M. neoaurum & 99 & M. neoaurum & 99.1 \\
\hline 3-AZ & 2 & Stonebrink & 1428 & M. neoaurum & 98 & M. neoaurum & 98.2 \\
\hline 5-AZ & 3 & Stonebrink & 1416 & M. neoaurum & 99 & M. neoaurum & 99.2 \\
\hline 8-AZ & 4 & Middlebrook & 1415 & M. neoaurum & 99 & M. neoaurum & 99.0 \\
\hline 12-AZ & 2 & Middlebrook & 1415 & M. neoaurum & 99 & M. neoaurum & 99.4 \\
\hline $4-\mathrm{AZ}$ & 4 & Middlebrook-P & 1420 & M. parafortuitum & 99 & M. parafortuitum & 98.2 \\
\hline 9-AZ & 3 & Middlebrook & 1415 & M. parafortuitum & 99 & M. parafortuitum & 98.9 \\
\hline $10-\mathrm{AZ}$ & 4 & Stonebrink & 1411 & M. parafortuitum & 99 & M. parafortuitum & 98.4 \\
\hline 11-AZ & 3 & Stonebrink & 1414 & M. parafortuitum & 99 & M. parafortuitum & 98.2 \\
\hline $6-A Z$ & 2 & Stonebrink & 1455 & M. moriokaense & 99 & M. moriokaense & 98.2 \\
\hline 13-AZ & 4 & Stonebrink & 1417 & M. moriokaense & 98 & M. moriokaense & 98.2 \\
\hline 7-AZ & 2 & Middlebrook-P & 1420 & M. confluentis & 99 & M. confluentis & 99.1 \\
\hline
\end{tabular}

2: Zacazonapan Holstein-F; 3: Zacazonapan Holstein-F; 4: Zacazonapan Holstein-F.

M. moriokaense, and, finally, $8 \%(1 / 13)$ had $99 \%$ similarity with $M$. confluentis (Table 3 ).

The phylogenetic tree was formed with the genus $\mathrm{Myco-}$ bacterium and four of its species by which the phylogenetic relationships between the collection strains and the strains isolated in the present investigation were observed (Figure 1).

\section{Discussion}

The NTM species were isolated from samples of nasal exudate only, which eliminated the samples from one of the local farms of this study (Table 1). We found that the specific prevalence was $19.1 \%$ in herds of the south region of the State of Mexico. Similar studies in the United States, South Africa, Tanzania, and Brazil reported NTM prevalence values of
$3.4 \%, 24.5 \%, 7 \%$, and $7.8 \%$, respectively; therefore, the prevalence value found in this study lies within the range reported previously [26-29]. In this study, 13 of the 39 analyzed strains were identified as the NTM species $M$. neoaurum, $M$. moriokaense, M. confluentis, and M. parafortuitum.

M. neoaurum, a member of the Mycobacterium parafortuitum complex, is responsible for a broad spectrum of illnesses, most of them device related infections such as Hickman catheters, BROVIAC catheters, PICC lines [30-33], arteriovenous fistula that included a polytetrafluoroethylene graft [34], pace makers [35], and prosthetic valve endocarditis [36]. Immunocompromised patients holding these devices are the principal hosts, for example, patients suffering from cancer [32] and diabetics with renal failure [31, 33, 34] and heart problems [35]. M. neoaurum has also been isolated from 


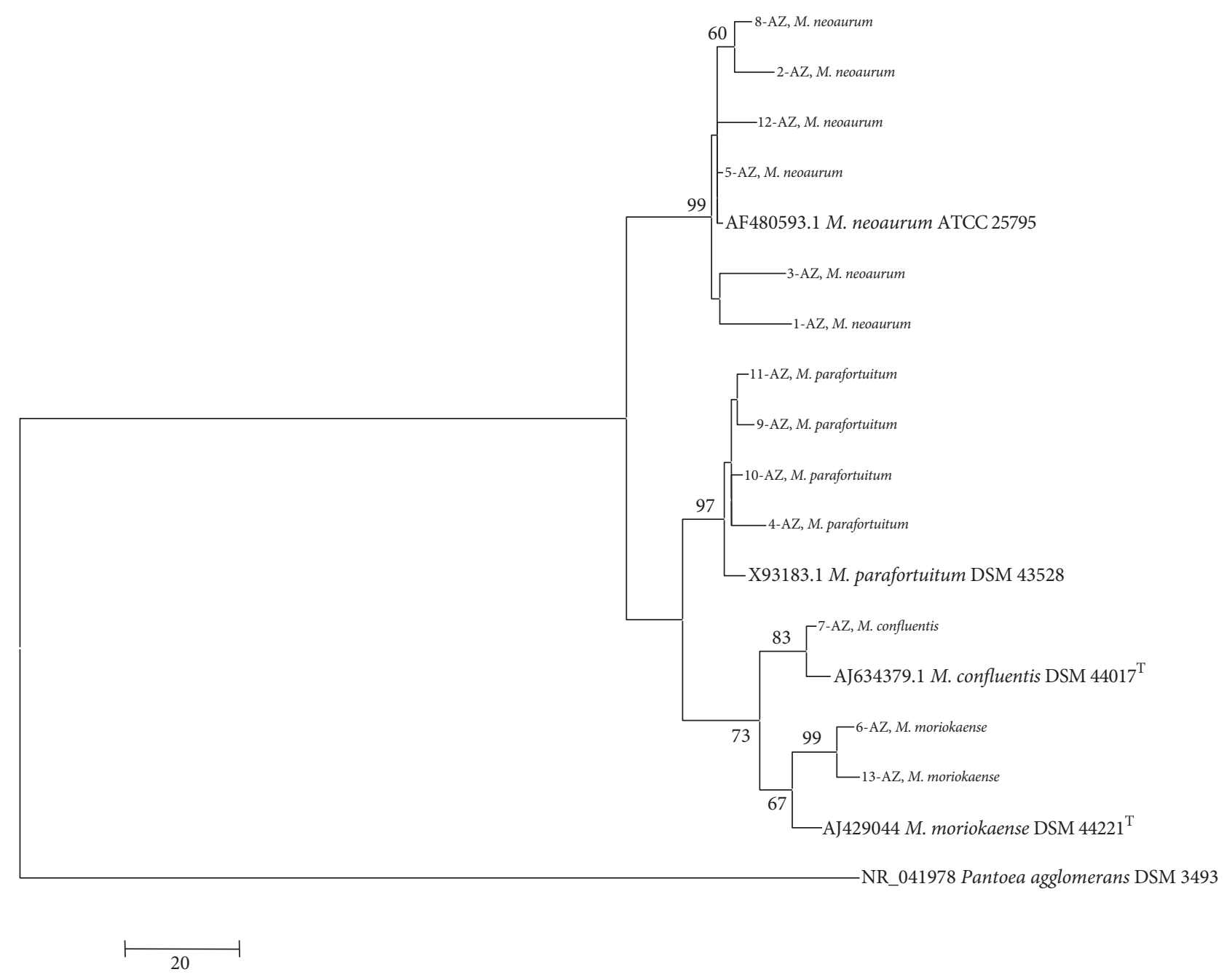

FIGURE 1: Phylogenetic tree constructed by comparing the 16S rRNA gene sequences from the isolated and reference strains.

patients with urinary infections [37], meningoencephalitis and alterations in the central nervous system [38], bacteremia and endocarditis [39], and pulmonary infection [40, 41]. Although it has been mainly isolated from clinical cases, there are also reports about its isolation from milk and cattle [28, 42, 43].

M. moriokaense was isolated from sputum sample [44]. Although it is considered nonpathogenic for humans, it has been associated with pulmonary diseases [45]. M. confluentis was isolated from sputum samples as well [46], and, along with $M$. parafortuitum, both are considered nonpathogenic species. M. confluentis, M. moriokaense, and M. neoaurum have been isolated from different bovine and wildlife tissues with tuberculous lesions, whereas $M$. parafortuitum has only been isolated from bovine milk [26, 28, 47-49]. However, in our work, $M$. parafortuitum was only isolated from nasal exudate samples.

The nutritional requirements of mycobacteria differ among various species, which was the reason for using different culture media. Notably, seven of the 13 strains identified in this study were isolated in Stonebrink medium, including
M. neoaurum, M. parafortuitum, and M. moriokaense. This result is consistent with that described by Sepúlveda et al. [50] who indicated that Stonebrink medium is suitable for the recovery of different species of the genus Mycobacterium. García-Martos and García-Agudo [51] reported that Middlebrook medium is optimal for the isolation of actinomycetes, which is in accord with the present investigation considering that two species, $M$. neoaurum and $M$. parafortuitum, were isolated in this medium. Notably, M. confluentis was isolated only in Middlebrook medium supplemented with sodium pyruvate; thus, the strategy of using different culture media was appropriate because it allowed the isolation of different species of the genus Mycobacterium.

The detection of the molecular marker present in the 23S rRNA gene of Gram-positive bacteria with HGC content allowed discrimination between strains of eubacteria and mycobacteria. The sequencing analysis of the 16S rRNA gene made the identification at the species level possible; therefore, the combination of these methodologies is appropriate for the identification of NTM species. 


\section{Conclusions}

Using the methodology described in this study, four NTM species were isolated and identified: $M$. confluentis, M. moriokaense, $M$. neoaurum, and M. parafortuitum. These species were isolated for the first time from nasal exudates of bovines from the south region of the State of Mexico. Three of the identified species ( $M$. neoaurum, $M$. moriokaense, and $M$. confluentis) are of public health and veterinary importance.

\section{Disclosure}

This work is derived from the thesis for the degree of Doctorate in Health Sciences (Universidad Autónoma del Estado de México), registered in the PNPC-CONACYT.

\section{Conflicts of Interest}

All authors declare that they do not have any conflicts of interest.

\section{Acknowledgments}

The authors would like to acknowledge the financial assistance from the Secretary of Research and Advanced Studies of Universidad Autónoma del Estado de México (UAEMex) through the following research grants: (i) "Implementation of Geographic Information Systems and Techniques of Molecular Biology, as tools in the detection and identification of Mycobacterium spp.," SIEA-UAEM 3486/2013CHT, and (ii) the network "Microbiología y química en las Ciencias de la Salud," 039/2014RIF.

\section{References}

[1] A. Aranaz, D. Cousins, A. Mateos, and L. Domínguez, "Elevation of Mycobacterium tuberculosis subsp. caprae Aranaz et al. 1999 to species rank as Mycobacterium caprae comb. nov., sp. nov," International Journal of Systematic and Evolutionary Microbiology, vol. 53, no. 6, pp. 1785-1789, 2003.

[2] M. H. Ho, C. K. Ho, and L. Y. Chong, "Atypical mycobacterial cutaneous infections in Hong Kong: 10-Year retrospective study," Hong Kong Medical Journal, vol. 12, no. 1, pp. 21-26, 2006.

[3] SAGARPA, "Norma Oficial Méxicana NOM-ZOO-031-1995 Campaña Nacional contra la Tuberculosis bovina (M. bovis)," Diario Oficial de la Federación, vol. 1996, pp. 12-32, 1995.

[4] O. R. G. Llamazares, C. B. G. Martín, D. A. Nistal, V. A. D. L. P. Redondo, L. D. Rodríguez, and E. F. R. Ferri, "Field evaluation of the single intradermal cervical tuberculin test and the interferon- $\gamma$ assay for detection and eradication of bovine tuberculosis in Spain," Veterinary Microbiology, vol. 70, no. 1-2, pp. 55-66, 1999.

[5] SENASICA, "Informes de la Situación Zoosanitaria Nacional de 2016," 2016, http://www.gob.mx/cms/uploads/attachment/ file/169575/SITUACION_ZOOSANITARIA_2016-11-8.pdf.

[6] M. D. Cave, K. D. Eisenach, P. F. McDermott, J. H. Bates, and J. T. Crawford, "IS6110: Conservation of sequence in the Mycobacterium tuberculosis complex and its utilization in DNA fingerprinting," Molecular and Cellular Probes, vol. 5, no. 1, pp. 73-80, 1991.
[7] S. R. Acosta, C. C. Estrada, and S. F. Milián, “Tipificación de cepas de Mycobacterium bovis," Técnica Pecuaria en México, vol. 47, pp. 389-412, 2009.

[8] C. Roller, W. Ludwig, and K. H. Schleifer, "Gram-positive bacteria with a high DNA $\mathrm{G}+\mathrm{C}$ content are characterized by a common insertion within their 23S rRNA genes," Journal of General Microbiology, vol. 138, no. 6, pp. 1167-1175, 1992.

[9] B. A. Zaragoza, C. M. Á. Karam, M. L. P. Bustamante, T. Á. H. Sandoval, and D. N. Ramírez, "Marcador molecular de actinomicetos utilizado para detectar micobacterias en muestras de esputo," Revista Mexicana de Ciencias Farmacéuticas, vol. 45, pp. 35-40, 2014.

[10] J. E. Clarridge, "Impact of $16 \mathrm{~S}$ rRNA gene sequence analysis for identification of bacteria on clinical microbiology and infectious diseases," Clinical Microbiology Reviews, vol. 17, no. 4, pp. 840-862, 2004.

[11] D. O. Sanjay, M. D. Avani, and D. O. James, "Atypical Mycobacterial cutaneous infections," Dermatologic Clinics, vol. 27, no. 1, pp. 63-73, 2009.

[12] S. Weitzul, P. J. Eichhorn, and A. G. Pandya, "Nontuberculous mycobacterial infections of the skin," Dermatologic Clinics, vol. 18, no. 2, pp. 359-377, 2000.

[13] H. M. Al-Abdely, S. G. Revankar, and J. R. Graybill, "Disseminated Mycobacterium simiae infection in patients with AIDS," Journal of Infection, vol. 41, no. 2, pp. 143-147, 2000.

[14] H.-S. Jang, J.-H. Jo, C.-K. Oh et al., "Successful treatment of localized cutaneous infection caused by Mycobacterium scrofulaceum with clarithromycin," Pediatric Dermatology, vol. 22, no. 5, pp. 476-479, 2005.

[15] J. J. Meyer and S. S. Gelman, "Multifocal osteomyelitis due to Mycobacterium szulgai in a patient with chronic lymphocytic leukemia," Journal of Infection, vol. 56, no. 2, pp. 151-154, 2008.

[16] D. Wagner and L. S. Young, "Nontuberculous mycobacterial infections: a clinical review," Journal of Infection, vol. 32, no. 5, pp. 257-270, 2004.

[17] K. P. Redbord, D. A. Shearer, H. Gloster et al., "Atypical Mycobacterium furunculosis occurring after pedicures," Journal of the American Academy of Dermatology, vol. 54, no. 3, pp. 520-524, 2006.

[18] P. Tang, S. Walsh, C. Murray et al., "Outbreak of acupunctureassociated cutaneous Mycobacterium abscessus infections," Journal of Cutaneous Medicine and Surgery, vol. 10, no. 4, pp. 166169, 2006.

[19] INEGI, “Censo Agrícola, Ganadero y Forestal 2007,” 2007, http:// www.inegi.org.mx/est/contenidos/proyectos/Agro/ca2007/Resultados_Agricola/default.aspx.

[20] B. A. Zaragoza, M. L. P. Bustamante, T. Á. H. Sandoval, and D. N. Ramírez, "Spatial analysis of bovine tuberculosis in the State of Mexico, Mexico," Veterinaria Italiana, vol. 53, no. 1, pp. 29-37, 2017.

[21] OPS, “Organización Panamericana de la Salud para el diagnóstico bacteriológico de la tuberculosis, Normas y guía técnica," Parte I Basiloscopia, 2008.

[22] T. A. Hall, "BioEdit: a user. friendly biologycal sequence alignment editor ana analysis program for Windows 95/98/NT," Nucleic Acids Symposium Series, vol. 41, no. 41, pp. 95-98, 1999.

[23] S. F. Altschul, T. L. Madden, J. Zhang, Z. Zhang, W. Miller, and D. J. Lipman, "Gapped BLAST and PSI-BLAST: a new generation of protein database search programs," Nucleic Acids Research, vol. 25, no. 17, pp. 389-402, 1997. 
[24] J. Chun, J.-H. Lee, Y. Jung et al., "EzTaxon: a web-based tool for the identification of prokaryotes based on $16 \mathrm{~S}$ ribosomal RNA gene sequences," International Journal of Systematic and Evolutionary Microbiology, vol. 57, no. 10, pp. 2259-2261, 2007.

[25] K. Tamura, J. Dudley, M. Nei, and S. Kumar, "MEGA4: molecular evolutionary genetics analysis (MEGA) software version 4.0," Molecular Biology and Evolution, vol. 24, no. 8, pp. 15961599, 2007.

[26] T. C. Thacker, S. Robbe-Austerman, B. Harris, M. V. Palmer, and W. R. Waters, "Isolation of mycobacteria from clinical samples collected in the United States from 2004 to 2011," BMC Veterinary Research, vol. 9, pp. 100-110, 2013.

[27] N. Gcebe, V. Rutten, N. C. Gey van Pittius, and A. Michel, "Prevalence and distribution of non-tuberculous mycobacteria (NTM) in cattle, African buffaloes (syncerus caffer) and their environments in South Africa," Transboundary and Emerging Diseases, vol. 60, supplement 1, pp. 74-84, 2013.

[28] B. Z. Katale, E. V. Mbugi, L. Botha et al., "Species diversity of non-tuberculous mycobacteria isolated from humans, livestock and wildlife in the Serengeti ecosystem, Tanzania," BMC Infectious Diseases, vol. 14, no. 1, pp. 1-8, 616, 2014.

[29] M. M. J. Franco, A. C. Paes, M. G. Ribeiro et al., "Occurrence of mycobacteria in bovine milk samples from both individual and collective bulk tanks at farms and informal markets in the southeast region of Sao Paulo, Brazil," BMC Veterinary Research, vol. 9, pp. 1-8, 2013.

[30] L. L. Washer, J. Riddell, J. Rider, and C. E. Chenoweth, "Mycobacterium neoaurum bloodstream infection: report of 4 cases and review of the literature," Clinical Infectious Diseases, vol. 45, no. 2, pp. e10-e13, 2007.

[31] H. Awadh, M. Mansour, and M. Shorman, "Bacteremia with an unusual pathogen: Mycobacterium neoaurum," Case Reports in Infectious Diseases, vol. 2016, Article ID 5167874, 3 pages, 2016.

[32] M. B. Davison, J. G. McCormack, Z. M. Blacklock, D. J. Dawson, M. H. Tilse, and F. B. Crimmins, "Bacteremia caused by Mycobacterium neoaurum," Journal of Clinical Microbiology, vol. 26, pp. 762-764, 1988.

[33] C.-C. Lai, C.-K. Tan, C.-C. Chen, and P.-R. Hsueh, "Mycobacterium neoaurum infection in a patient with renal failure," International Journal of Infectious Diseases, vol. 13, no. 5, pp. e276-e278, 2009.

[34] M. L. Becker, A. A. Suchak, J. N. Wolfe, R. Zarychanski, A. Kabani, and L. E. Nicolle, "Mycobacterium neoaurum bacteremia in a hemodialysis patient," Canadian Journal of Infectious Diseases, vol. 14, no. 1, pp. 45-48, 2003.

[35] E. J. Hayton, O. Koch, M. Scarborough, N. Sabharwal, F. Drobniewski, and I. C. Bowler, "Rapidly growing mycobacteria as emerging pathogens in bloodstream and device-related infection: a case of pacemaker infection with Mycobacterium neoaurum," JMM Case Reports, vol. 2, no. 1-3, 2015.

[36] A. Kumar, G. S. Pazhayattil, A. Das, and H. A. Conte, "Mycobacterium neoaurum causing prosthetic valve endocarditis: a case report and review of the literature," Brazilian Journal of Infectious Diseases, vol. 18, no. 2, pp. 235-237, 2014.

[37] S. Zanetti, R. Faedda, G. Fadda et al., "Isolation and identification of Mycobacterium neoaurum from a patient with urinary infection," New Microbiologica, vol. 24, no. 2, pp. 189-192, 2001.

[38] G. A. Heckman, C. Hawkins, A. Morris, L. L. Burrows, and C. Bergeron, "Rapidly progressive dementia due to Mycobacterium neoaurum meningoencephalitis," Emerging Infectious Diseases, vol. 10, no. 5, pp. 924-927, 2004.
[39] B. A. Brown-Elliott, R. J. Wallace Jr., C. A. Petti et al., "Mycobacterium neoaurum and Mycobacterium bacteremicum sp. nov. as causes of mycobacteremia," Journal of Clinical Microbiology, vol. 48, no. 12, pp. 4377-4385, 2010.

[40] Y. Morimoto, E. D. Chan, L. Heifets, and J. M. Routes, "Pulmonary infection with Mycobacterium neoaurum identified by 16 S ribosomal DNA sequence," Journal of Infection, vol. 54, no. 4, pp. e227-e231, 2007.

[41] C.-K. Kim, S. I. Choi, B. R. Jeon, Y.-W. Lee, Y. K. Lee, and H. B. Shin, "Pulmonary infection caused by mycobacterium neoaurum: the first case in Korea," Annals of Laboratory Medicine, vol. 34, no. 3, pp. 243-246, 2014.

[42] S. A. Sgarioni, R. D. C. Hirata, M. Hiroyuki Hirata et al., "Occurrence of Mycobacterium bovis and non-tuberculous mycobacteria (NTM) in raw and pasteurized milk in the northwestern region of Paraná, Brazil," Brazilian Journal of Microbiology, vol. 45, no. 2, pp. 707-711, 2014.

[43] L. Padya, N. Chin'Ombe, M. Magwenzi, J. Mbanga, V. Ruhanya, and P. Nziramasanga, "Molecular identification of mycobacterium species of public health importance in cattle in zimbabwe by 16 S rRNA gene sequencing," Open Microbiology Journal, vol. 9, pp. 38-42, 2015.

[44] M. Tsukamura, I. Yano, and T. Imaeda, "Mycobacterium moriokaense sp. nov., a rapidly growing, nonphotochromogenic Mycobacterium," International Journal of Systematic Bacteriology, vol. 36, no. 2, pp. 333-338, 1986.

[45] A. Somoskovi and M. Salfinger, "Nontuberculous mycobacteria in respiratory infections: advances in diagnosis and identification," Clinics in Laboratory Medicine, vol. 34, no. 2, pp. 271-295, 2014.

[46] P. Kirschner, A. Teske, K.-H. Schroder, R. M. Kroppenstedt, J. Wolters, and E. C. Bottger, "Mycobacterium confluentis sp. nov," International Journal of Systematic Bacteriology, vol. 42, no. 2, pp. 257-262, 1992.

[47] M. Pate, U. Zajc, D. Kušar et al., “Mycobacterium spp. in wild game in Slovenia," Veterinary Journal, vol. 208, pp. 93-95, 2016.

[48] L. Botha, N. C. Gey van Pittius, and P. D. van Helden, "Mycobacteria and disease in Southern Africa," Transboundary and Emerging Diseases, vol. 60, no. 26, pp. 147-156, 2013.

[49] J. J. Camarena Miñana and R. González Pellicer, "Micobacterias atípicas y su implicación en patología infecciosa pulmonar," Enfermedades Infecciosas y Microbiología Clínica, vol. 29, no. 5, pp. 66-75, 2011.

[50] A. Sepúlveda, P. M. García, M. J. Rodríguez, A. Márquez, and J. L. Puerto, "Evaluación del medio de Stonebrink para la recuperación de micobacterias," Revista de Diagnóstico Biológico, vol. 50, pp. 189-192, 2001.

[51] P. García-Martos and L. García-Agudo, "Infecciones por micobacterias de crecimiento rápido," Enfermedades Infecciosas y Microbiología Clínica, vol. 30, no. 4, pp. 192-200, 2012. 


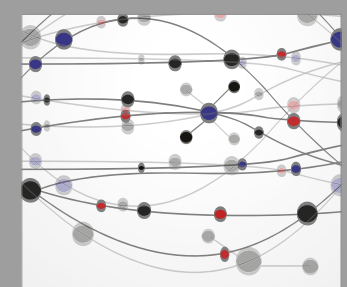

The Scientific World Journal
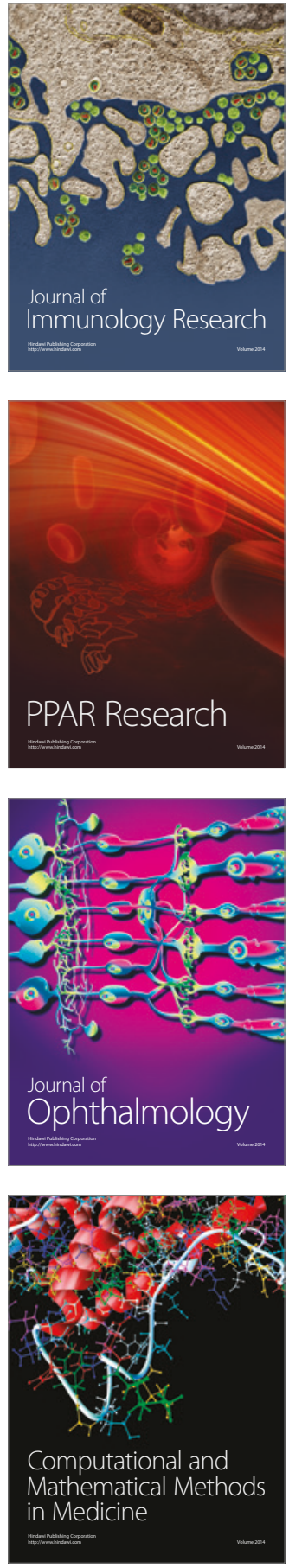

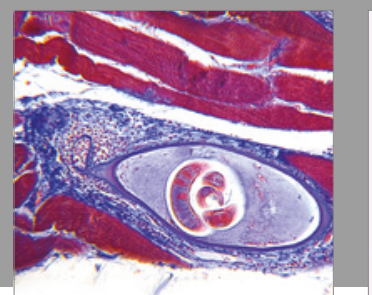

Gastroenterology Research and Practice
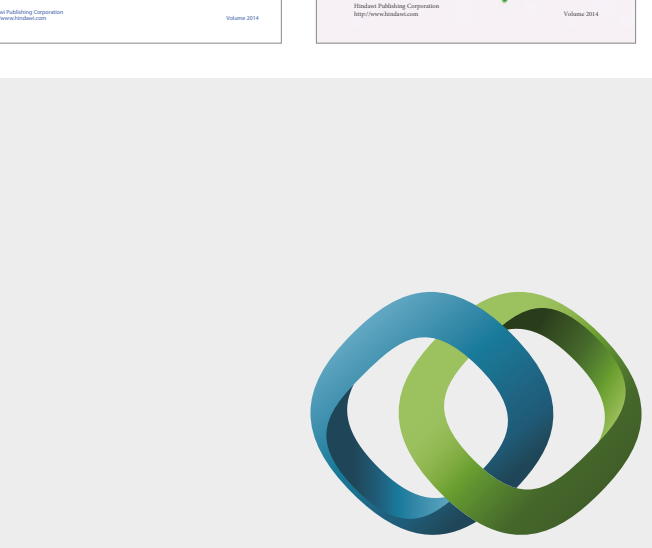

\section{Hindawi}

Submit your manuscripts at

https://www.hindawi.com
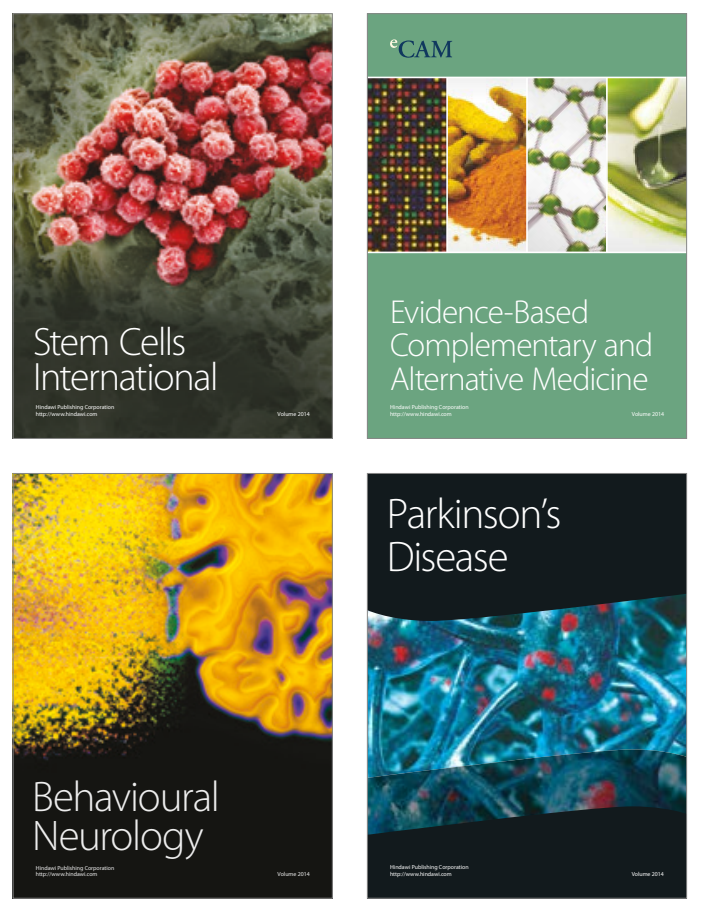
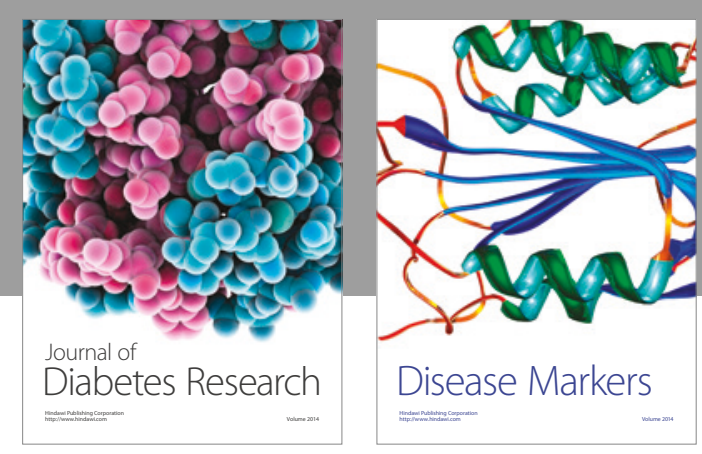

Disease Markers
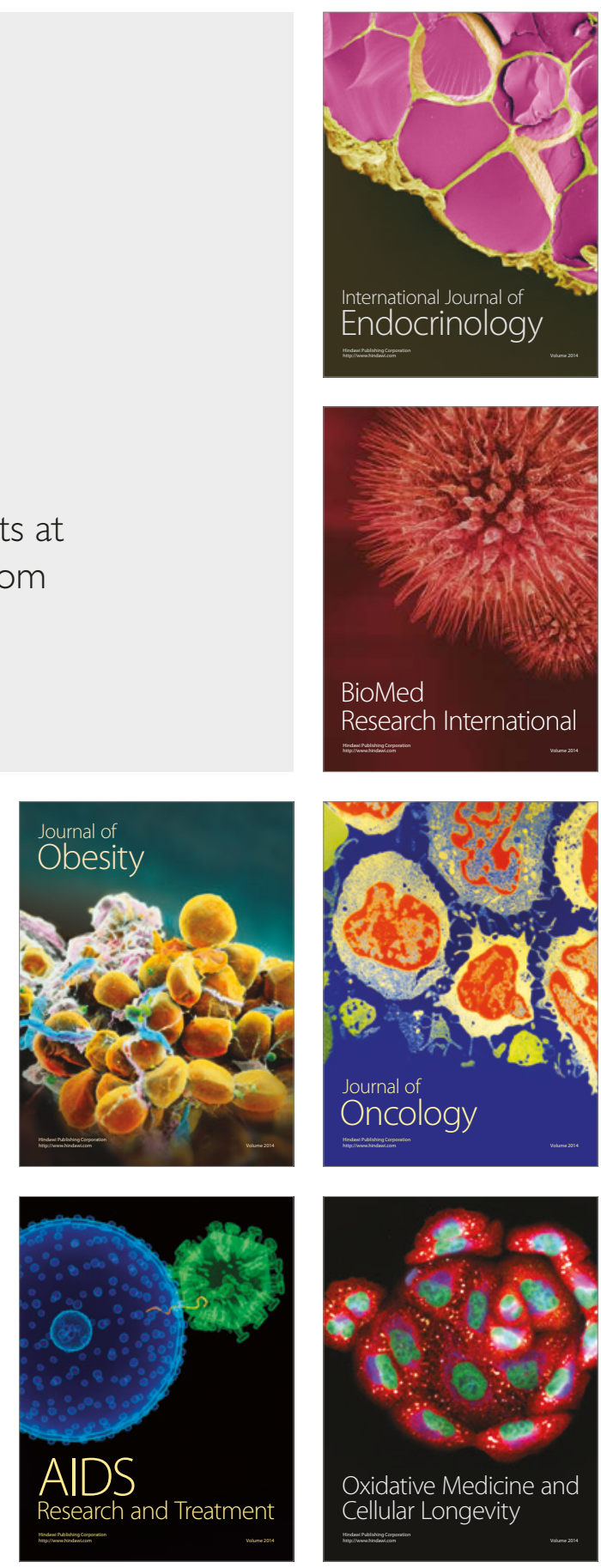